\title{
Exploration on the Ability Cultivation of New Engineering System in Beijing Institute of Fashion Technology
}

\author{
Jinshan Feng ${ }^{1,}$ a, $\mathrm{HaO} \mathrm{Ma}^{1, \mathrm{~b}^{*}}$ and Hao Liü, \\ ${ }^{1}$ Information Engineering School Beijing Institute of Fashion Technology \\ agxymh@bift.edu.cn, ${ }^{\text {b}} 52059676 @ q q . c o m$, cgxyliuh@bift.edu.cn
}

\begin{abstract}
Keywords: New engineering; Art and craft integration; System capability; Innovation consciousness
\end{abstract}

\begin{abstract}
With the development of new technologies, the professional construction of new engineering is in progress. The system capability, which is suitable for the new engineering to respond to changes and lead innovation actively, is the basic guarantee for the professional innovation in the context of new engineering. By discussing about the students' system ability training, the reform and optimization of systemic competence, training status and training measures, the students in the art and craft integrator of Beijing Institute of Fashion Technology will have a more comprehensive knowledge of the basic theory, system ability of the major, systematic understanding. Thus, improving students' ability to solve complex engineering problems and innovation consciousness will be improved, the new engineering construction will be highly promoted by cultivating outstanding professional engineering talents which can adapt to the changes of epoch and future.
\end{abstract}

\section{Introduction}

With the rapid development and wide application of new technologies such as artificial intelligence, big data, cloud computing, and Internet of Things, a computing model with multiple computing platforms such as embedded computing, mobile computing, parallel computing, intelligent computing, and service computing has been formed[1]. The object of processing presents the characteristics of network, multimedia, big data and intelligent demand. Under this new situation, the requirements for the training of professional talents in colleges have changed greatly as well. Universities should better adapt to these changes and develop talents with sustainable competitiveness.

Beijing Institute of Fashion Technology, as one of the most well-known clothing and fashion colleges and universities at home and abroad, the number of graduates and the number of students accounted for $30 \%$ respectively in the field of engineering[2]. In the professional construction and education upgrading of new engineering, system capacity training is the first important content, and it has more urgent requirements than ever before. Under the new situation of rapid development and wide application of information technology, system capability training has great significance and influence on the training level and quality of engineering students in our school. in theoretical and practical.

\section{System Capacity Training Connotation}

With the establishment of large-scale data centers and the widespread use of personal mobile devices, the "procedural development capabilities" emphasized by the original computer professional training are being transformed into "systematic design capabilities" for engineering majors[3]. In order to deal with a variety of complex computer applications, and to write a variety of efficient programs for different professions, application developers should understand the underlying structure of different professions, master the techniques know the tools, and cultivate the overall system view of the corresponding technical field as well as the ability to penetrate software and hardware collaborative design. In terms of these respects, the gap is very huge between Chinese 
universities and developed countries in the world. System capability plays an important role in engineering professionals.

The system is a combination of several interconnected, interacting and interdependent components, which is an organic ensemble with certain structure and function under certain environment. System capabilities are the ability to design and develop system structures to achieve engineering goals that based on defined system capabilities.

Computer systems involving system capacity development can be divided into three levels.

(1) Using mathematical and physical principles to design and develop computer operating systems, including central processing units (CPUs), operating systems, and compilation systems. This is the most basic system of computers called computer basic systems. The related courses include digital logic, computer composition, operating system, and compilation system, etc.

(2) Using computer basic system principles, designing and developing specialized systems in the computer field, such as software development systems, database systems, network systems, support systems, platform systems, etc., are called computer domain systems.

(3) Using computer professional system principles to design and develop various application systems, such as digital manufacturing systems, driverless systems, wireless communication systems, etc., called computer application systems.

The goals of system capacity training are to transform and upgrade the engineering education of existing higher education institutions, strengthen the training of engineering professional system ability, promote the deep integration of knowledge, ability and quality requirements of high-tech and computer majors, explore the implementation path of engineering professional transformation and upgrading. And improve students' overall quality and ability to adapt to the development of the new economy.

System capacity training and system view education are applicable to all majors of engineering and all training directions. We need to accumulate a wealth of teaching resources, form valuable practical experience, and continue to improve the level of engineering education and quality of personnel training with systematic ability training.

\section{System Capacity Training Status}

At present, the research and reform of engineering majors in Beijing Fashion College is not enough to reform and pay attention to the system ability training. Therefore, the students who are trained have some problems in system ability, which cannot meet the requirements of social, disciplinary technology development and employer[4]. First of all, the complete concept of system capability system cannot be well established, and the system concept is not enough to solve the problem at the system level. Secondly, the core content of the computer system is not enough, and most engineering students are difficult to handle complex software/hardware collaborative design. Thirdly, the students' comprehensive analysis, design and application skills are also poor because the content of the professional courses is not well established. Finally, the systematic and comprehensive practice links are lacking, and the students' practical skills are poor.

At present, a new system-level comprehensive curriculum in the teaching of theoretical knowledge is engineering in the field of professional education, and strengthening system knowledge, re-planning the core curriculum of computer systems, will connect the content of these core coursely. The overall system is stronger; at the same time, it is necessary to strengthen the system practical ability training, and focus on the construction of a sufficient supporting practice environment and content.

System capacity training modes in Beijing Fashion Institute has the following:

(1) Adopting the introduction of teaching materials and open courses of famous schools, or drawing on foreign teaching methods, experiments and processes, and working closely with foreign universities.

(2) Integrate the content of the course group and carry out systematic practice. The core content of the core curriculum group, computer composition, operating system, compilation technology and other teaching content are planned, connecting the practice links. 
(3) Carrying out the practice teaching reform, the reform idea is the integration and reconstruction of the curriculum system, according to the inherent logical relationship of the system structure, combing the knowledge system of the course group, realizing the physical synthesis of computer hardware and software on the unified hardware experiment platform, and gradually establishing and deepening the system. Concept.

The application of the above model for system capacity training has achieved good progress and results. In the past three years, in order to further in-depth study and practice system capacity training, China Electronic Education Association also organized the many activities such as National University System Capacity Training Summit Forum, China Computer Education Conference, China Computer Conference System Capacity Training Forum, etc. For thematic exchanges; organized the system in terms of competence, research on new courses and the preparation of new textbooks; planning investment specialization to support the research and practice of system capacity training; conducting national university-wide teacher training and teaching, including theoretical teaching content and practical teaching links of relevant courses, and started the system capacity training competition and so on.

\section{Measures for the Training of New Engineering System Capabilities}

We should study and analyze the new requirements of the new economy for the training of traditional engineering professionals, investigate some practices and ideas of undergraduate in foreign universities, and explore the general idea of curriculum system reform suitable for the cultivation of China's higher education system by combining the information technology with social development trends in the intelligent era and the characteristics of talent training in China's colleges and universities when faced to artificial intelligence, big data, new technologies such as cloud computing and Internet of things. In the teaching of theoretical knowledge of engineering majors, it is necessary to establish a new system-level comprehensive curriculum, strengthen system knowledge, and re-plan the core curriculum of computer systems, so that the links between these core curriculum contents will be closer, the connection will be smoother, and the overall system sexuality will be stronger. Also, it is necessary to strengthen the system practice ability training in order to solve the problem of weak system practice.

We should focus on research and build a sufficient supporting practice environment and content, and strengthen the corresponding system practice ability training in an important position[5]. All colleges and universities should combine their own characteristics and provide strong support in practical platforms and content. On the basis of the existing methods, we will accumulate a wealth of teaching resources, form valuable practical experience, and continue to improve the level of engineering and the quality of personnel training with the training of systemic competence. The specific measures and research methods mainly include the following aspects.

(1) In-depth analysis and research, and propose reform plans. Organize research groups to conduct in-depth investigations, analysis and research at home and abroad; propose and establish a new undergraduate course system for engineering, re-plan the contents of the core courses of computer systems; and study the evaluation criteria for the level of training of new engineering professional systems.

(2) Promote the promotion of model institutions. Under the new engineering knowledge structure and curriculum system, it is necessary to further promote the system capacity training of the model colleges, conduct in-depth research and analysis on the system knowledge, system ability and system curriculum of engineering students, and further enhance the system capacity training of the pilot schools. guide.

(3) Summarize the pilot experience and promote it nationwide. According to the characteristics and objectives of the institutions, the pilot work will be carried out in a solid manner, and the effective practices, curriculum contents, practical environment and content of the system capacity training research practice will be promoted and applied to universities across the country according to different types and levels. 
(4) Strengthen teacher training, speed up the preparation of teaching materials, and publish relevant teaching research papers. Promote the theoretical and practical training of teachers' system competence, accelerate the preparation of new textbooks with systemic capacity training as the core, and especially focus on the development of the curriculum materials for the development of level courses.

(5) Check the communication promotion. Measure the overall system capacity training level and promote its improvement through the implementation of system capacity training standards. Promote mutual learning among universities, and mobilize students' enthusiasm for systematic and in-depth study.

\section{Conclusion}

System capability is the basic guarantee for professional innovation in the context of new engineering. System capacity training will actively improve students' innovation ability, which is very suitable for the new engineering department to actively respond to changes, lead the requirements of innovation and the goal of "double-class" to improve the quality of undergraduate students. Through the process of system capacity training, we will continue to explore new concepts, new structures, new models, new quality, and new systems of engineering education in the context of new economic changes, and cultivate outstanding engineering professional engineering talents that can adapt to the times and future changes, and promote new in-depth development of engineering construction.

\section{Acknowledgements}

This research was financially supported by Beijing Institute of Fashion Technology under Grant NHFZ20180104/007and NHFZ20180087/048.

\section{References}

[1] Gefang Zhen, Huaiyu Liu and Liurong Hong, et al. Reorientation of Computer System Capability Cultivation under the Background of New Engineering[J]. Computer Knowledge and Technology, 2017, (36): 133-134.

[2] Zhou Development, Yuzhen Zeng. Exploration of core competence and teaching mode of new engineering[J]. Chongqing Higher Education Research, 2017, (3): 22-35.

[3] Tianfu Yuan, Xiaoli Zhao, Wei Jiang, Wei Jin and Yujin Zhang. Reflections on the Construction of Teaching Staff in the Background of New Engineering[J]. China Modern Educational Equipment, 2017, (23): 22-23, 38.

[4] Dongjun Huang. Research on the Course Setting of Internet of Things Specialty in the Context of New Engineering[J]. Computer Education, 2018, (3): 68-72.

[5] Junqing Fan, Gaifang Wang. Construction of New Engineering Practice Platform Based on Internet of Things Project[J]. Laboratory Technology and Management, 2017, (12): 179-182, 199 